\title{
Digital Image Processing Equipment
}

National Cancer Institute

\section{Source}

National Cancer Institute. Digital Image Processing Equipment. NCI Thesaurus. Code C69194.

Equipment used to analyze, enhance, interpret or display digital images. 